\title{
RESULTS OF EXPERIMENTAL RESEARCH IN SEPARATOR DIELECTRIC ASPIRATION CHANNEL
}

\author{
Olexiy Shokarev $^{1}$, Serhii Kiurchev ${ }^{1}$, Oleksandr Shokarev ${ }^{1}$, Anatolii Rud ${ }^{2}$, Oleg Gorbovy ${ }^{2}$ \\ ${ }^{1}$ Tavria State Agrotechnological University, Ukraine; \\ ${ }^{2}$ State Agrarian and Engineering University in Podillia, Ukraine \\ alexandr.shokarev@gmail.com,dakgps@pdatu.edu.ua
}

\begin{abstract}
Aerodynamic seed separators are the simplest and most bionically grounded. Therefore, it is necessary to use exactly such machines for separation, having previously increased their efficiency. It is determined that not enough attention has been devoted by scientists to justification of parameters and operation modes of vertical freefall aspiration machines and influence of the electric field on the working process of such separator. We propose an experimental unit of an aspiration seed separator with a dielectric channel. In it, seeds are separated and dispersed according to their specific mass when falling in a counter air flow, as well as when interacting with an electric field. The effective length of the dielectric aspiration channel of the separator is one of the important technical parameters. It has a critical influence on the seed separation process. The hypothesis assumes that, if the vertical channel length is short, there will be little splitting of the vertical seed trajectory. As a result, this will lead to the negative effect of the migration of poor quality light seeds of the technical fraction into the seed fraction. The value of the input voltage on the outer surface of the dielectric aspiration channel of the separator also has a significant influence on the total quality of the separator function. As a result of the interaction, the light seeds, closest to the side walls with the bifilar coil, begin to split their vertical trajectory additionally by the force of electrical attraction when they are moving from top to bottom. Therefore, in the course of the experimental research the rational value of voltage feeding on the electrodes of bifilar coil located on the outer surface of separator's aerodynamic channel is found. The article presents methods and results of laboratory research and calculations of rational length of the dielectric aspiration channel of the separator and rational value of the feeding voltage on the bifilar coil. As a result of researches the dependence of the radius of seed dispersion on the length of the vertical dielectric channel of the separator was obtained. The analysis of the parameters of the proposed installation is given. The obtained experimental parameters allow developing a concept of the aspiration seed separator with a dielectric channel, which will improve the quality of seeds and reduce the cost of seed preparation.
\end{abstract}

Keywords: separator, aspiration channel, bifilar coil.

\section{Introduction}

The use of modern intensive farming technologies is one possible way of increasing the profitability of crop production. Such technologies place high demands on seeds, as it is one of the factors increasing the yields. Separation of the most biologically valuable seeds from the total mass is a reliable way of increasing crop yields. It allows an additional 10-25\% yield compared to unseparated seeds [1-3]. This also applies to sunflowers, both cultivar-population and small-seeded hybrids. Scientists in many countries of the world are concerned with the problems of seed separation [4-8]. The existing designs of sunflower seed separation machines with different operating principles have a number of drawbacks that reduce the quality of seed separation as a result [2;9].

However, not enough attention has been devoted by scientists to substantiate the parameters and modes of operation of vertical free-fall aspiration machines, also the influence of the electric field on the working process of such a separator has not been considered [9]. When separating sunflower seeds, it is planned to use an aerodynamic separator with a dielectric coil at the stationary point. It is supposed that seeds are taken from the hopper by the feeder through the inlet pipe to the aerodynamic vertical channel with dielectric strand. At falling of seeds inside the channel under the action of gravity, the air stream and the electric field created by a dielectric coil, placed on the outer surface of this channel, which has been made of plastic, are sucked up towards them. As a result of the interaction of aerodynamic and electric forces, a splitting of the vertical trajectory of the seeds with their subsequent redistribution in the fraction of specific-heavy seeds and specific-light seeds takes place. To justify the basic engineering and technological parameters of the proposed separator it is necessary to carry out experimental research in order to confirm the results of theoretical studies.

\section{Materials and methods}

An experimental installation of the proposed seed separator with a dielectric channel has been designed and manufactured. The source of the air flow of the separator is an axial fan 8 (Fig. 1). A 
vertical channel 6 is attached to the fan. On the surface of the dielectric channel 6 there is a bifilar coil 10 with two single wires connected to the power supply 11. In the lower part of the separator, in the place of seed output from the dielectric channel 6, is placed a divider 9, which can be two- or three-stage (respectively divide into 2 or 3 fractions). Seed fractionation sections are made as steel pipe elbows (similar in design to the air duct elbows with $90^{\circ}$ rotation angle).

The elbows of the fraction divider are placed at an angle of $90^{\circ}$ with each other, and consequently the elbows pass through each other by means of openings. The smaller diameter elbow, which is inside the larger diameter elbow, forms the divider for selecting the most biologically valuable seeds into fraction I. Respectively, the larger diameter elbows are used to select from the separated seeds into fractions II and III.
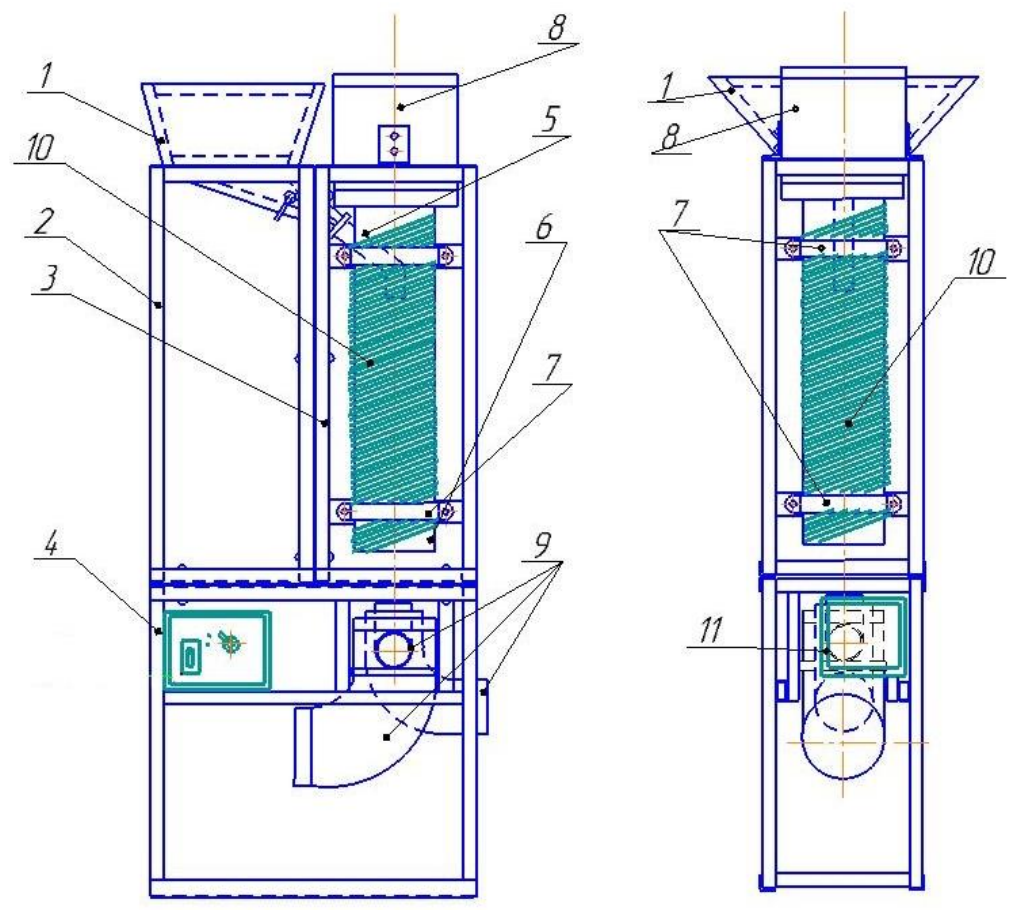

Fig. 1. Scheme of experimental installation of aerodynamic seed separator: 1 - hopper; 2 - hopper support; 3 - dielectric channel frame; 4 - main bearing frame 5 - seed inlet pipe; 6 - plastic tube of vertical dielectric channel; 7 - bottom bracket of dielectric channel; 8 - fan; 9 - dividing unit for separated seeds; 10 - bifilar coil of dielectric channel; 11 - high voltage source for bifilar coil

In the upper part of the central part of the section axis of the dielectric vertical channel there is a seed input tube 9 . The seed inlet tube is installed with an inclination to the side of seed sliding, enters it from the hopper 8 and feeds seed to the point of inlet (Fig. 1). The seed feeding device from the hopper - hopper feeder has a regulating flap, which in the process of operation has the possibility to change operatively the amount of seed feeding by overlapping cross-section of the hopper outlet 1.

The aerodynamic seed separator works as follows. From the hopper 8 the seeds pass through the feeder (which has a regulating flap), from where they are fed through the seed inlet pipe 10 to the elbow 9. As a result, the seeds are fed strictly in the center of the vertical section axis of the upper part of the dielectric aspiration channel 4 with the bifilar coil 10 (Fig. 1). The axial fan through the feed regulator and fixed in the upper part of the dielectric vertical aspiration channel of the separator generates a vertical air flow directed towards the seeds falling from above, i.e., the air flow moves from bottom to top [9-11]. Seeds, when falling in the air stream, as well as when interacting with the electric field (created by the bifilar coil 10 fed by the high voltage current source 11) are separated and dispersed depending on their specific weight. The most biologically valuable, specific-weight seeds do not change their trajectory downwards, so they fall without dispersion in the minimum diameter spigot of fraction I. Specific light seeds have a non-ideal surface shape, low specific weight and as a result fall into fractions II and III. 
Rational length of the vertical aspiration channel of the separator is one of the important constructive parameters having defining influence on the process of seed separation [9;12]. If the length of the vertical channel is not enough, low value of splitting of vertical trajectory of seeds will be obtained, as a result, it will lead to negative effect of migration of low-quality specific light seeds of technical fraction II - to seed fraction I. Thus, the length of the vertical dielectric channel of the separator must have a rational value.

To determine a rational value of length of the separator's vertical dielectric channel during experimental research we will make series of researches according to the following procedure. Determine a rational airflow rate inside the separator vertical channel. We will set the air flow speed in the middle of the vertical dielectric channel of the separator by changing the rotation frequency of the axial fan. Control the speed by means of the electric meter of low air flow speed. The value of the supply voltage on the outer surface of the separator dielectric aspiration channel also has a significant influence on the overall quality of the developed separator. When the vertical trajectory is divided by a counterflow of rational speed, the lightest seeds come close to the side walls, where they are additionally affected by the electric field of the bifilar coil, formed by coiling an isolated wire with electrodes of electric polarity alternating with each other. As a result of the interaction of the closest to the side walls with the bifilar coil, the specific light seeds start to split their vertical trajectory additionally by the force of the electrical attraction when they move from the top to the bottom. Thus, in the course of experimental research it is necessary to establish a rational value of supply voltage at the electrodes of the bifilar coil, located on the outer surface of the aerodynamic channel of the separator. For each value of the supply voltage on the bifilar coil is necessary to measure the absolute distance of the split radius of the vertical trajectory of the seeds, by measuring the distance from the nearest side wall of the projection of the outer diameter of the vertical channel to the target for seed fixation. After measuring the distance by repeating the experiment three times, we plot the average value of the distance of the seed trajectory from its own weight interval.

An experimental prototype of a vertical dielectric separator channel with the possibility of changing its length is presented for research (Fig. 2). An electromagnetic controlled valve 3 is installed in the feed tube 4, which will open the lower end of the electromagnetic relay at the right time, and the seeds inside the feed tube will fall inside the vertical dielectric channel.

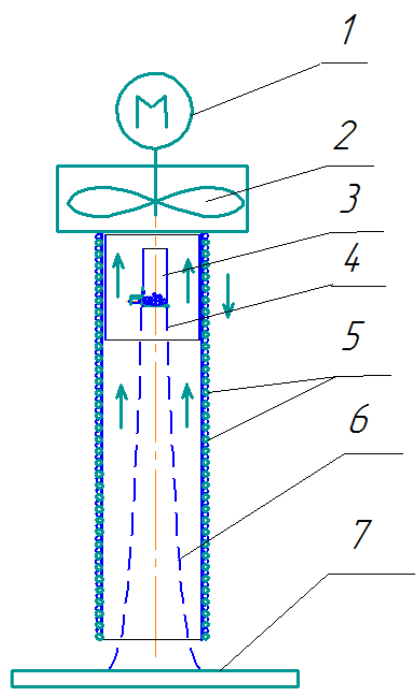

Fig. 2. Schematic diagram of installation for investigation of rational length of vertical dielectric channel of separator: 1 - electric motor; 2 - axial fan; 3 - electromagnetic valve; 4 - feed tube; 5 - bifilar coil; 6 - spigot; 7 - fixing target

In the research, inside the feeder tube 4 (Fig. 2), unseparated seeds of the previous fraction at the right time, when the air flow of the required speed and there is a rational value of the supply voltage on the bifilar coil 5, with an electric voltage of $12 \mathrm{~V}$, the relay will open the electromagnetic valve 3 , and the seeds will fall into the working cavity of the vertical channel. 
As a result of the interaction, seeds of different specific weight will split their vertical trajectory and hit the fixing target 7.

By measuring the maximum radius of separation of the most specific light seeds, when the distance of seed flight is increased from $0.3 \mathrm{~m}$ to $0.9 \mathrm{~m}$, a diagram will be plotted and a conclusion about the rational length of the vertical dielectric flow of the separator will be concluded.

\section{Researchanddiscussion}

As a result of the experimental research, a diagram of the dependence of the distance between the seeds with the lowest specific weight and the speed of the air flow inside the vertical aspiration channel of the separator was plotted (Fig. 3).

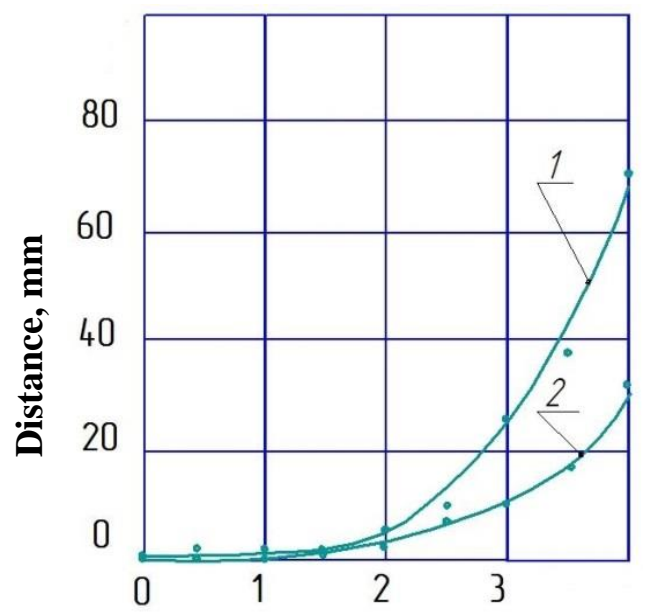

Flow speed, $\mathbf{m} \cdot \mathbf{s}^{-1}$

Fig. 3. Diagram of split vertical trajectory distance of specific light seeds in dielectric channel as function of flow speed: 1 - mass $0.05-0.055 \mathrm{~g} ; 2$ - mass $0.055-0.06 \mathrm{~g}$

On the results of the diagrams obtained the conclusion was made that the rational value of the air flow speed in the middle of the vertical separator channel is the speed close to the critical one of the most specific light seeds, i.e. $3.5-4 \mathrm{~m} \cdot \mathrm{s}^{-1}$.

The data obtained in the course of the experiments were used to plot (Fig.4) the dependence of the separation distance of specific-light seeds with self-weight interval of 0.05-0.055 $\mathrm{g}$ and $0.055-0.06 \mathrm{~g}$ on the value of the feeding voltage of the bifilar coil of the outer surface of the separator aspiration channel.

As a result of analysis of the diagram in Fig.4, a conclusion is reached that a preliminary accepted rational value of the supply voltage of the aspiration channel bifilar coil of the separator is in the range $3.5-5 \mathrm{kV}$.

At putting the supply voltage of $3.5-5 \mathrm{kV}$ we get additional splitting of the vertical trajectory of the heaviest seeds in the range 11.4-12.8\%.

However, since the value of the supply voltage from $4.5 \mathrm{kV}$ and above leads to sticking with subsequent retention on the inner surface of the vertical dielectric aspiration channel most of the specific-light seeds, the rational value of the supply voltage bifilar coil is accepted $3.5-4 \mathrm{kV}$.

In the course of the experimental research on determining the rational length of the dielectric aspiration channel of the separator, on the basis of the obtained data the diagram of dependence of the separator's seed dispersion radius on the length of the vertical dielectric channel (Fig. 5) was plotted.

Analyzing the data in Fig. 5, it is found that the most rational length of the vertical aspiration channel of the suggested separator is $0.8 \mathrm{~m}$ with the speed of air flow inside this aspiration channel with the dielectric coil in the range $3.5-4.0 \mathrm{~m} \cdot \mathrm{s}^{-1}$, because the change of the trajectory of heavy seeds is much more than light ones. Consequently, the heavier seeds will fall into the valuable fraction. It is at these values of the length of the vertical aspiration channel with the dielectric coil of the separator (effective 
length between the seed input device, the feeding tube and the lower end of this channel) that the difference in the seed dispersion radius is $10-12 \mathrm{~mm}$.

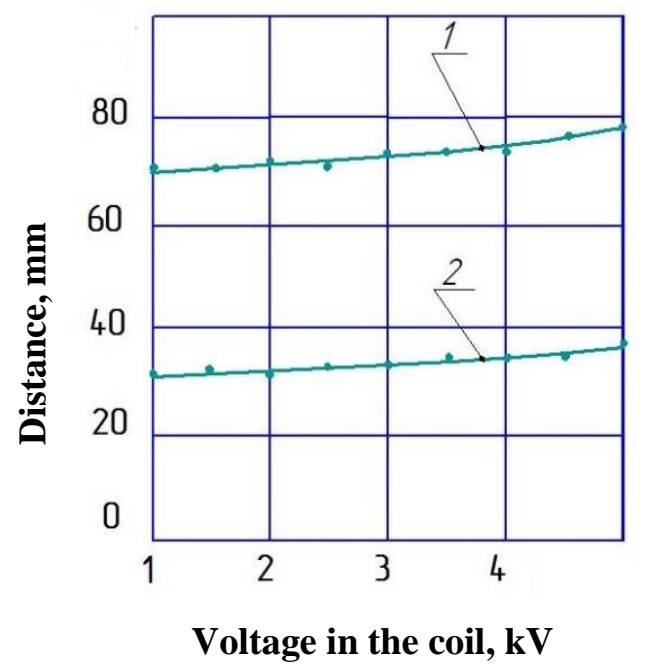

Fig. 4. Diagram of the dependence of the splitting distance of the vertical trajectory of specific light seeds in a dielectric channel with air flow of $4 \mathrm{~m} \cdot \mathrm{s}^{-1}$ onthe value of the supply voltage

fabifilar coil: 1 - mass of $0.05-0.055 \mathrm{~g} ; 2$ - mass of $0.055-0.06 \mathrm{~g}$

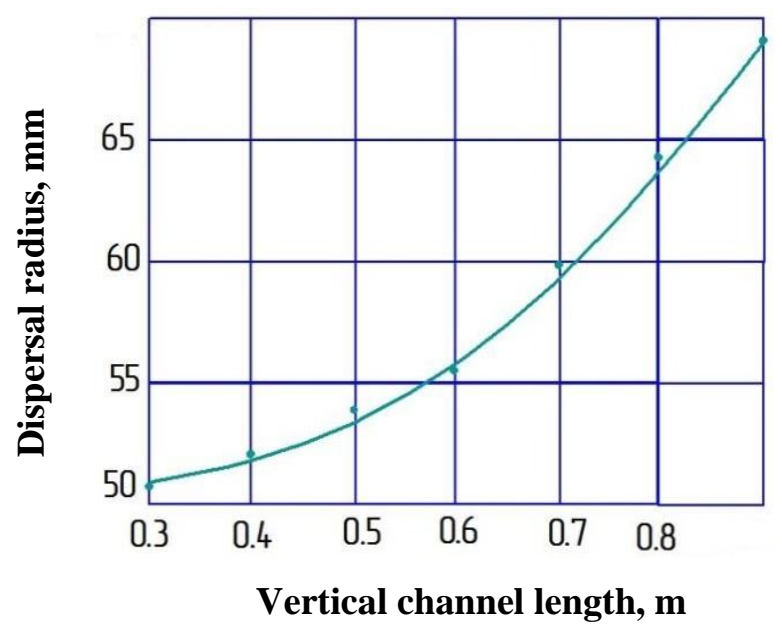

Fig. 5. Diagram as function of vertical channel length for seed dispersal radius (specific-light)

During the experimental research of the presented aerodynamic separator with a dielectric coil for comparative analysis a pneumogravitational separator of sunflower seeds was taken as a prototype [9]. In both studies sunflower seed of the cultivar-population was used. Since only specific-heavy seeds to be used for sowing are of value, light seeds weighing less than $0.059 \mathrm{~g}$ were not studied. The fractional composition of seeds was from $0.059 \mathrm{~g}$ to $0.099 \mathrm{~g}$. During the research of the prototype, the following results were obtained: the rational value of air flow rate in the middle of the vertical separator channel $-5.5 \mathrm{~m} \cdot \mathrm{s}^{-1}$, the rational length of the channel $-0.8 \mathrm{~m}$, with a capacity of $90 \mathrm{~kg} \cdot \mathrm{h}^{-1}$ [9]. In the investigation of the presented aerodynamic separator with dielectric winding it was found that the rational capacity of the separator is $107 \mathrm{~kg} \cdot \mathrm{h}^{-1}$, at that the length of the vertical dielectric channel of the separator was also $0.8 \mathrm{~m}$, the speed of the air flow in the dielectric channel was $4 \mathrm{~m} \cdot \mathrm{s}^{-1}$. That is, the separator capacity has increased with the reduction of the energy capacity of the fan.

\section{Conclusions}

The results of the experimental research allow to create algorithmic models and software to calculate the main structural and technological parameters of the proposed aerodynamic separator. These methods will allow to make calculations and produce industrial samples of separators of the developed type with given capacity not only for different sunflower cultivars, but also for other oilseeds. 
The developed and obtained graphical and textual recommendations will allow to carry out technological adjustment of existing machines, which will be manufactured for separating of sunflower seeds with specified parameters.

\section{References}

[1] Kotov B.I. Perspectives of development of grain-cleaning machinery designs) // Design, manufacture and operation of agricultural machinery: Kirovohrad. 2001. Vol. 31. p. 110-111. (In Ukrainian).

[2] Shokarev O.M., Shokarev O.O.,Kyurchev S., Shegeda K.O. Analysis of devices for separation of combed crop heap) // Bulletin of Tavria State Agrotechnological University [Electronic resource].Melitopol: TSATU, 2014. - Vol. 4, T.2., pp. 136-145. [online] [21.03.2021] Available at: http://nauka.tsatu.edu.ua/e-journals-tdatu/e-index.html. (In Ukrainian).

[3] Bulgakov V., Nikolaenko S., Holovach I. etc. Theory of motion of grain mixture particle in the process of aspiration separation. Agronomy Research 18(S2), 2020. pp. 1177-1188.

[4] Selig M.S. Wind Tunnel Testing Airfoils at Low Reynolds Numbers/M.S. Selig, R.W. Deters, G.A. Williamson. // 49th AIAA Aerospace Sciences Meeting, AIAA Paper 2011-875, Orlando, FL, 4-7 January 2011, pp. 1-32.

[5] Desai B.B., Kotecha P.M., Salunkhe D.K. Seeds handbook: biology, production, processing, and storage. Marcel Dekker, Inc., New York, 1997.

[6] Jorgensen K.R., Stevens R. Seed collection, cleaning, and storage, Chap. 24. In: Stephen B. Monsen, Richard Stevens, and Nancy Shaw (compilers), Restoring Western Ranges and Wildlands. USDA Forest Service Gen. Tech. Rep. RMRS-GTR-136. Ft. Collins, Colorado. 2004.

[7] Dewald C.L., Beisel V.A., Sims P.L. Concepts and principles of the Woodward chaffy seed conditioning system, p.278-282. In: G.W. Frasier and R.A. Evans (eds.), Seed and Seedbed Ecology of Rangeland Plants, USDA-ARS, Washington, D.C., 1987.

[8] Tishchenko L.N. To research On the study of the separation of fractions of a grain mixture during separation on a vertical cylindrical vibrocentrifugalsievee/L.N. Tishchenko, M.V. Piven // Vibrations in machinery and technology. - 2002. -No. 5(31). - p. 40-43. (In Russian)

[9] Kolodiy O.S. Substantiation of constructive - technological parameters of the pneumogravity separator of sunflower seeds: dis .. k-ta.tekhn.nauk: 05.05.11/TSATU. Melitopol, 2015. 140p.

[10] Yermakov S., Hutsol T., Ovcharuk O., Kolosiuk I. Mathematic simulation of cutting unloading from the bunker. Independent journal of management \& amp; production (IJM\&P). Vol. 10, No. 7. 2019. pp. 758-777.

[11] Yermakov S., Hutsol T., Mudryk K. etc. The analysis of stochastic processes in unloading the energy willow cuttings from the hopper. Environment, Technology, Resources. In Proceedings of the 12 th International Scientific and Practical Conference, 2019, Rezekne, Latvia, pp. 249-252. DOI: $10.17770 /$ etr2019vol3.4159

[12] Malkina V., Kyurchev S., Osadchyi V., Strokan O. The formation of orthogonal balanced experiment designs based on special block matrix operations on the example of the mathematical modeling of the pneumatic gravity seed separator. Modern Development Paths of Agricultural Production Trends and Innovations, Part I, P. 111-120, Melitopol, Tavria State Agrotechnological University. 2019. 